\title{
Multidisciplinary Approach to a Recovery Plan of Historical Buildings
}

\author{
Luciana Orlando \\ Dipartimento di Ingegneria Civile, Edile e Ambientale, Sapienza Università di Roma, Via Eudossiana 18, 00184 Roma, Italy \\ Correspondence should be addressed to Luciana Orlando, luciana.orlando@uniroma1.it
}

Received 17 February 2011; Accepted 23 May 2011

Academic Editor: Francesco Soldovieri

Copyright () 2011 Luciana Orlando. This is an open access article distributed under the Creative Commons Attribution License, which permits unrestricted use, distribution, and reproduction in any medium, provided the original work is properly cited.

The paper emphasizes the advantages of employing multiple data techniques-geology, GPS, surveys of cracking, boreholes, seismic refraction and electrical resistivity tomography - to image the shallow stratigraphy and hypothesize the cause of instability of an urban area. The study is focused on the joint interpretation of the crack pattern, topographic monitoring and the features of the underground, to define the area affected by instability and the direction of ground motion with the objective to advance a hypothesis on the cause of the instability of the area and to depict the main features. Borehole stratigraphies for a univocal interpretation of the lithology of electrical and seismic data and electrical resistivity tomography to constrain the interpretation of the lateral velocity variations and thickness of seismic bedrock were used. The geophysical surveys reveals to be complementary in the depicting of underground features. The study is approached at small and medium scale.

\section{Introduction}

Over the past 10 years, buildings in the centre of the village of Roccaspinalveti, located in central Italy (Figure 1(a)), have shown progressive damage on a time lapse of 7 years. The instability revealed itself suddenly, and with time the increment of damage decreased until becoming null. In most cases, the instability was revealed via cracks and fractures in the walls and floors of buildings, as well as in the roads (Figure 2). The cracks have a displacement of less than 0.1 to $2 \mathrm{~cm}$, and most are located at the building-to-road contact (Figure 2(b)). The buildings, built in the late nineteenth century through today and with different materials and techniques, have all suffered the same sort of damage. Initially, many buildings were reclaimed with micropiles and resined but without any restoration plan based on objective data. Following restoration, some of the buildings have been affected by further instability. Thus, the municipality recognized the need to perform a detailed study of the instability phenomena; this study was conducted from 2004 to 2009.

For an exhaustive analysis of the area affected by instability, a multidisciplinary approach is generally considered in order to constrain the data interpretation. The data can be used for a joint interpretation [1-4] or for a joint inversion [5-9]. The first is often highly dependent on the experience of interpreter, and the second depends heavily on the algorithms, the quality of data, and so forth. In literature we often find that the joint inversion is performed with some parameters constrained (speed, thickness, resistivity, etc.) and/or using an iterative processes based on more data. In any case, a joint inversion can be very complex to apply for a large number of investigations and to a wide and complex subsoil.

Due to the complexity of the phenomena of instability and of the geological setting of the area, knowledge of topography, morphology, geology, hydrogeology, slit image, and so forth, of fundamental importance for the remediation plan, was considered. Direct and indirect surveys were planned, processed, and interpreted, jointly, in such a way as to obtain information needed to design the remediation plan. In detail, direct and indirect methods were applied, such as mapping of cracks, boreholes, geology, GPS monitoring, electrical resistivity tomography, and seismic refraction. All the data were interpreted jointly to reduce the intrinsic uncertainty of 


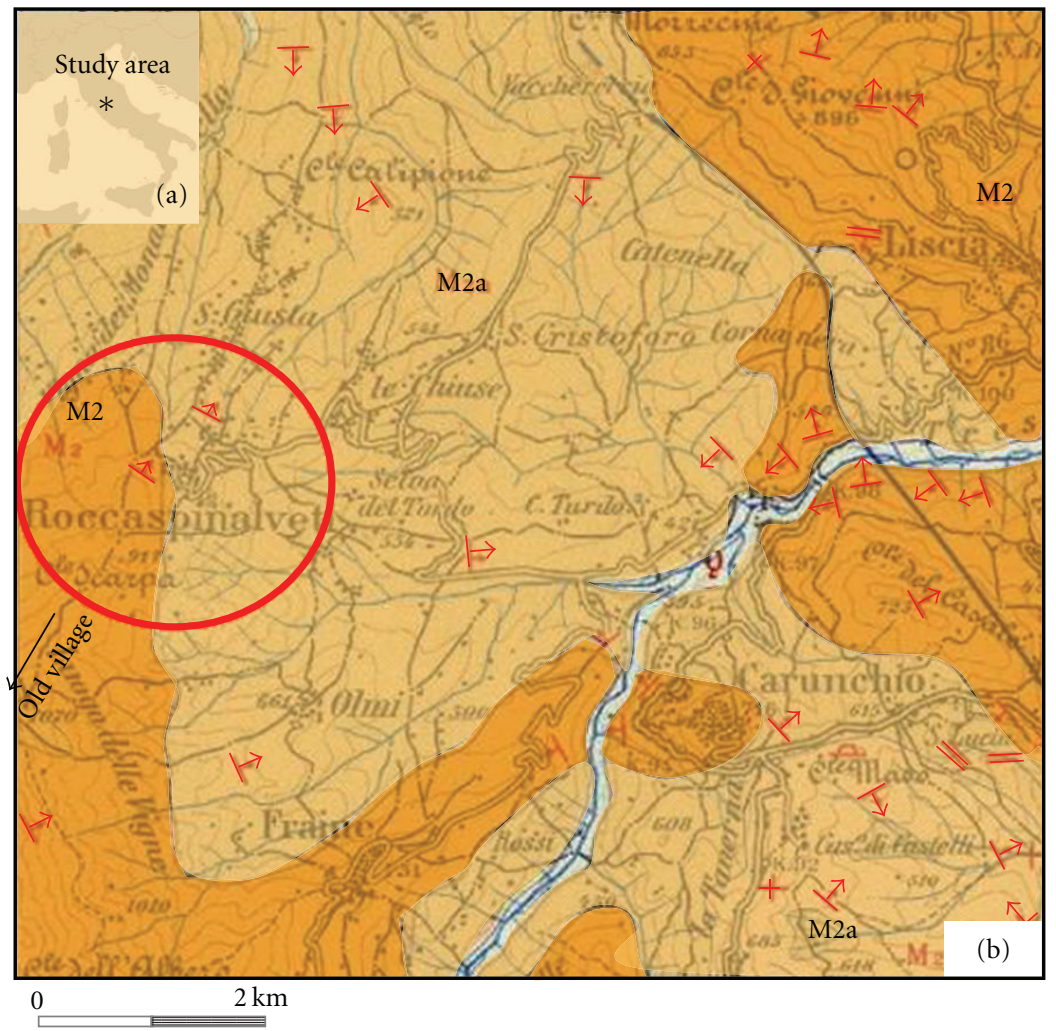

FIGURE 1: Study area location (a). The geological map (b) shows two outcropping formations Miocene in age: a flysch complex formed by a succession of calcareous sandstone, dense marl, clayey-marl-clay strata (M2), and a complex formed by a succession of clayey-sand and marl strata (M2a). The red arrows indicate the faults and the black arrow indicates the location of the old village $3 \mathrm{~km}$ from the present one.

each method and to reach the following main objectives:

(1) stratigraphy of the near surface sediments,

(2) determination of intensity and direction of the main ground motion,

(3) identification of the cause of instability.

The paper is mainly focused on the acquisition and joint interpretation of data rather than on the advanced inversion.

\section{Survey Methods}

The study of an urbanized area affected by instability problems is not a simple task. Geological evidence is often masked by structures that severely constrain the planning, location, and quality of the data. In such cases, geophysical methods can be applied, using special precautions to overcome problems due to environmental noise, road surface, hidden outcropping formations, fill material, small dimensions of walking areas, and so forth.

In this study, collection and joint analysis of all the existing data, the choice of the most suitable surveys, their accurate application and inversion, and a joint interpretation of the results were used to find a first answer to the starting questions concerning the geological setting of the unstable area and the most likely causes of the instability. The planning of the survey is shown in the flow chart of Figure 3.
The study was executed in three main steps: first, the morphology and geologic and cracks maps were analyzed (step $1)$; on the basis of these data, the boundary of the area affected by instability was outlined and the most suitable survey methods were defined (step 2); at the end the area was surveyed, the data were processed, and the results were interpreted jointly (step 3) with the aim of depicting the stratigraphy of the near surface soil and advancing a scenario of the cause of instability.

Below I describe each step in detail.

\subsection{Step 1. Step 1 includes}

(i) geo-hydro-morphology analysis,

(ii) crack surveys.

This step has the objective of planning topographic monitoring, geophysical surveys, and boreholes.

2.1.1. Geo-Hydro-Morphology. The village is $690-770 \mathrm{~m}$ above sea level, on a slope varying from 2\% to $10 \%$ (north west-south east) (Figure 4). Large-scale topography shows numerous nicks from landslides that have occurred in the past (dotted lines in the figure); in fact, a landslide in the mid-eighteenth century induced the population to migrate to the present-day village location (750 $\mathrm{m}$ above s.1.) from 


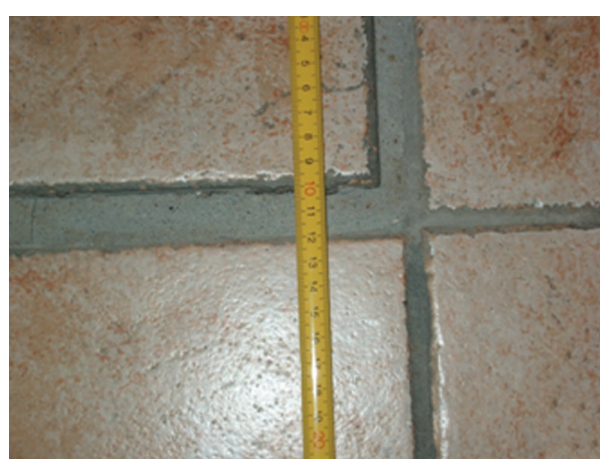

(a)

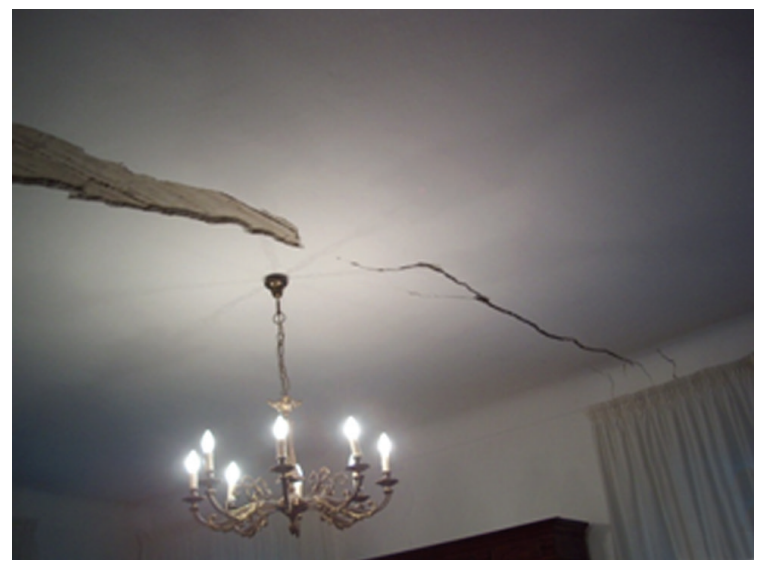

(c)

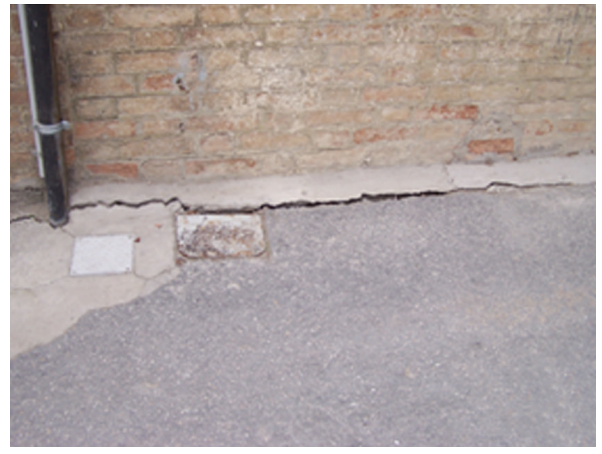

(b)

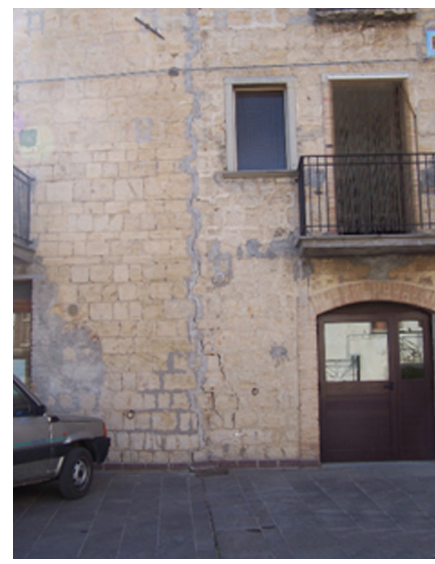

(d)

Figure 2: Photo images of cracks in the floor (a), road (b), ceiling (c), and building walls (d).

the old one, which was $1100 \mathrm{~m}$ above s.l. and $3 \mathrm{~km} \mathrm{SW}$ of today's village (Figure 1(b)).

The geological map (Figure 1(b)) shows that the village is located across two formations of Miocene age: a flysch complex formed by a sequence of calcareous sandstone, dense marl, clayey-marl-clay strata (M2) and a complex formed by a sequence of clayey-sand and marl strata (M2a). Such sequences can be over $100 \mathrm{~m}$ thick.

Excavation for building foundations has shown that, near the surface, the soil is formed by landfill deposits, clay of variable thicknesses, and marl.

In recent years the area has been affected by long periods of drought. Two points for pumping water have been activated in the proximity of a severely damaged building. These coeval events lead us to endorse the hypothesis that the instability could have been caused by compaction of sediments due to water table drawdown.

2.1.2. Crack Survey. The crack survey was based on interviews with householders, photographs, displacement measurements, and mapping on the cadastral map of the cracks visible in the roads and buildings. This approach was very time-consuming but fundamental in determining the direction of ground motion, because it allowed me to identify three main patterns of cracks and to outline the instability area where the surveys were focused.
Each pattern, formed by cracks more or less parallel to each other was marked with A, B and C in Figure 5(a).

Pattern A (Figure 5(a)) runs parallel to the road, and the cracks are located both inside the buildings and on the road. The main cracks have caused the detachment of the footpath from the buildings (Figure 2(b)). Pattern B (Figure 5(a)) is perpendicular to the $\mathrm{A}$ and $\mathrm{C}$ patterns and crosses roads and buildings (Figure 2(d)). Pattern C runs almost parallel to A and is nearly perpendicular to $\mathrm{B}$. This pattern was the most difficult to characterise as some of the buildings exhibit heavy damage while the roads are little affected. A careful analysis of the crack locations, and the setting of the area, led us to suppose that stress had induced a viscous deformation of roads that, in this area, are built on embanked materials.

From the analysis of crack map two main findings were established. First, most damaged buildings lie on the rupture alignments while the buildings fully located within the area surrounded by the rupture patterns A, B and C show either no cracks or only small ones. This indicates that the whole area located within the rupture alignments is not exposed to differential movement. The second finding is that the degree of damage is unrelated to age, materials, and techniques of construction as I have found no correlation between degree of damage and these building characteristics.

2.2. Step 2. In the second step, the most suitable techniques for outlining the study area were selected: reconstruction 


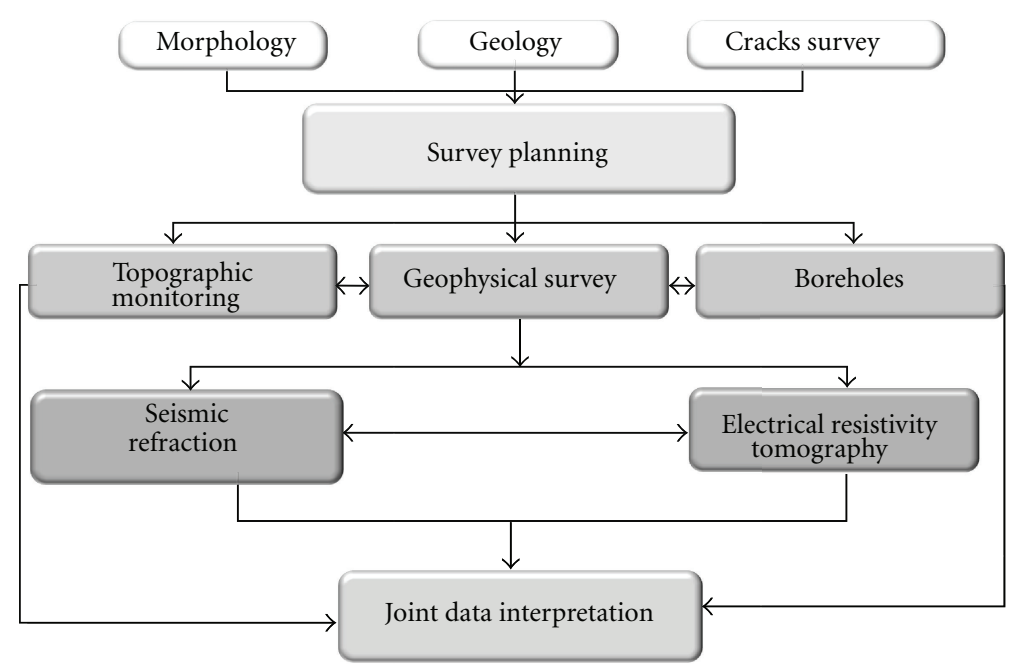

FIGURE 3: Flow chart of the surveys performed in the study area.

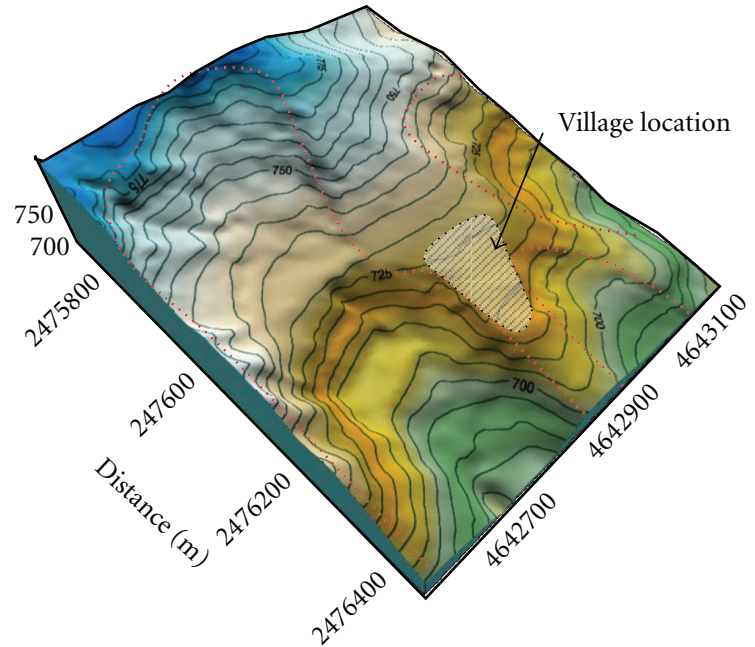

FIGURE 4: Morphology of the area. Dotted lines outline niches induced by landslides that occurred in the past.

of the geological setting and monitoring terrain movement over time. The topographic survey was chosen to assess the magnitude and terrain ground motion over time, boreholes to establish stratigraphy and constrain the ambiguity of the geophysical data interpretation in terms of thickness of strata and lithology, and seismic refraction and electric resistivity tomography to give lateral continuity to borehole stratigraphy in terms of geometries and lithologies. Seismic refraction and electric resistivity tomography were selected because I think that they are the most suitable, well-tested, and robust geophysical methods to outline the near surface stratigraphy.

2.2.1. Topographic Monitoring. The topographic measurements were performed on 7 GPS points (Figure 5(b)). The measurement points were equipped with brass pins inserted into holes drilled in the ground. The GPS (TopCon) RTK instrument was slotted onto these pins. The measurements were repeated 3 times in one year.

The GPS measurements indicate the following:

(1) Instability induces mainly vertical movement. The maximum value detected at point A (Figure 5(b)) was about $2 \mathrm{~cm}$ in six months.

(2) Only at point A, a significant lateral movement of about $4-5 \mathrm{~cm}$ was recorded, its direction is NNW to SSE, more or less parallel to the pattern of cracks A and $\mathrm{C}$ patterns (Figure 5(a)).

(3) The greatest displacements occurred in the summer season.

These results, combined with those obtained from the crack analyses, are consistent with the hypothesis of compaction of the near surface layers, consequent with lowering of the water table during long periods of drought and activation of two pumping points in the most unstable area (crack pattern A).

2.2.2. Boreholes. Two continuous coring boreholes (BH1 and $\mathrm{BH} 2$ ) and one destructive borehole ( $\mathrm{Sm} 1$ ) (white squares in Figure 5(c)) were drilled. The borehole stratigraphies indicate that the first $24 \mathrm{~m}$ of soil can be divided into two units: Unit A near the surface consisting of landfill clay deposits and clay interbedded with thin calcarenite layers, and Unit B, formed by fairly dense silty-marl strata.

In detail:

BH1 Borehole. The borehole BH1 is $24 \mathrm{~m}$ deep. Unit A extends from 0 to $13.7 \mathrm{~m}$ : from the top to 0.7 , it consists of landfill clay deposits and from 0.7 to $13.7 \mathrm{~m}$ of silty-clay, which becomes slightly sandy between 4 and $13.7 \mathrm{~m}$. At 3.5$5 \mathrm{~m}$, the silty-clay layer incorporates a humus organic soil related to ancient groundcover. This unit also includes thin calcarenite levels that become slightly sandy at 4-13.7 m. 


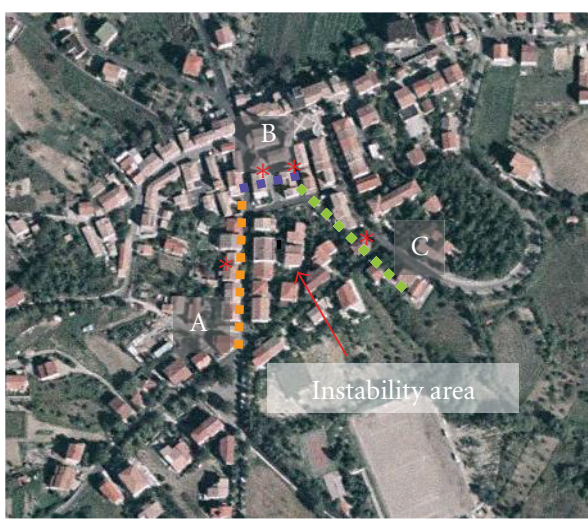

(a)

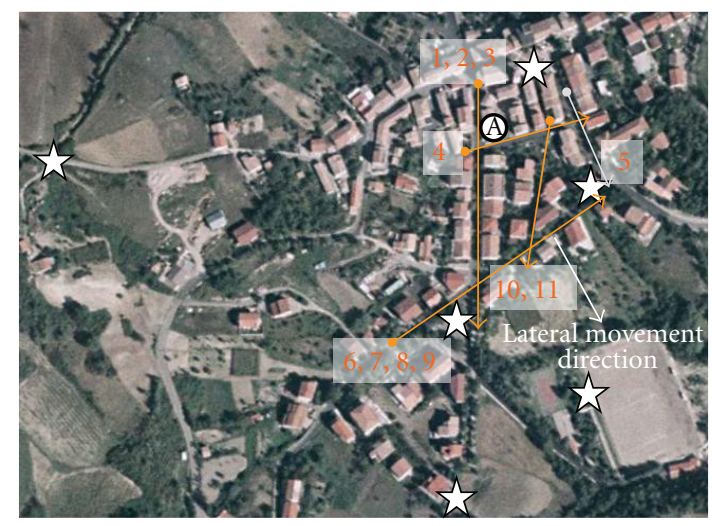

(b)

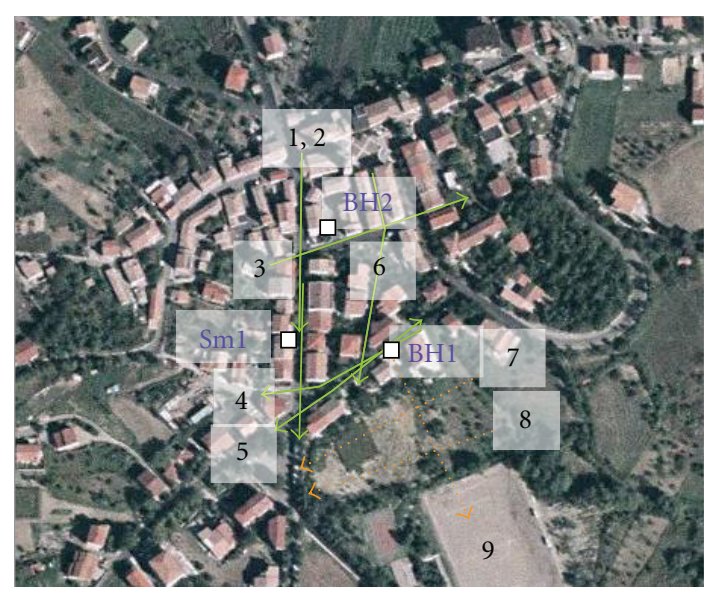

(c)

FIGURE 5: (a) Location of main crack patterns lying more or less normal to each other, the buildings with the greatest damage are marked with stars. (b) White circles and stars indicate location of topographic survey: stars indicate steady points and circles unsteady ones. Orange lines are the location of seismic refraction surveys. (c) Borehole locations are indicated with white squares and electric resistivity tomography with green and orange dot lines.

Unit B, from 13.7 to $24 \mathrm{~m}$, consists of water-saturated silty clay with small marl content. The water table was $13 \mathrm{~m}$ deep.

BH2 Borehole. This borehole is $15 \mathrm{~m}$ deep. Unit A, $9.3 \mathrm{~m}$ thick, consists, from 0 to $1.5 \mathrm{~m}$, of clay landfill deposits and silty-clay rich in carbonaceous fragments; clay and thin fractured limestone layers lie in the distance from 1.5 to $6.6 \mathrm{~m}$, and calcarenite from $6.6 \mathrm{~m}$ to $9.3 \mathrm{~m}$. Unit B consists mainly of dense silty-clay marl from 9.3 to $15 \mathrm{~m}$. Water eruption during drilling suggests the presence of a water overpressured layer.

Sm 3 Borehole. This borehole consists of Unit A from 0 to $6 \mathrm{~m}$ of depth and Unit B from $6 \mathrm{~m}$ to $8 \mathrm{~m}$. The stratigraphy was based on wash sample analysis.

The water table in the study area is located in Unit A at a depth from 1 to $13 \mathrm{~m}$.

\section{Step 3}

The well-tested and robust geophysical methods seismic refraction and electrical resistivity tomography for the near-
TABLE 1

\begin{tabular}{lc}
\hline Channel & 24 \\
Line lenght & $69 \mathrm{~m}$ \\
Receiver offset & $3 \mathrm{~m}$ \\
Shot offset & $-50,0,17.25,34.5,51.75,69,119 \mathrm{~m}$ \\
Receiver frequency & $7 \mathrm{~Hz}$ \\
\hline
\end{tabular}

surface investigation were selected to depict the geometry assessment and $\mathrm{P}$ wave velocity of the near-surface geological layers.

3.1. Seismic Refraction. The area was surveyed with 11 refraction seismic profiles located along the roads (Figure 5(b)) for a total length of $759 \mathrm{~m}$ with 2 overlapping receivers for lines in succession. The acquisition parameters are listed in Table 1.

The problem of the receiver coupling was overcome using receivers equipped with a metallic plate coupled to the road with mortar. The trigger was a receiver, and the source a dropped weight of $700 \mathrm{~kg}$ that was dropped onto the ground by a forklift. 


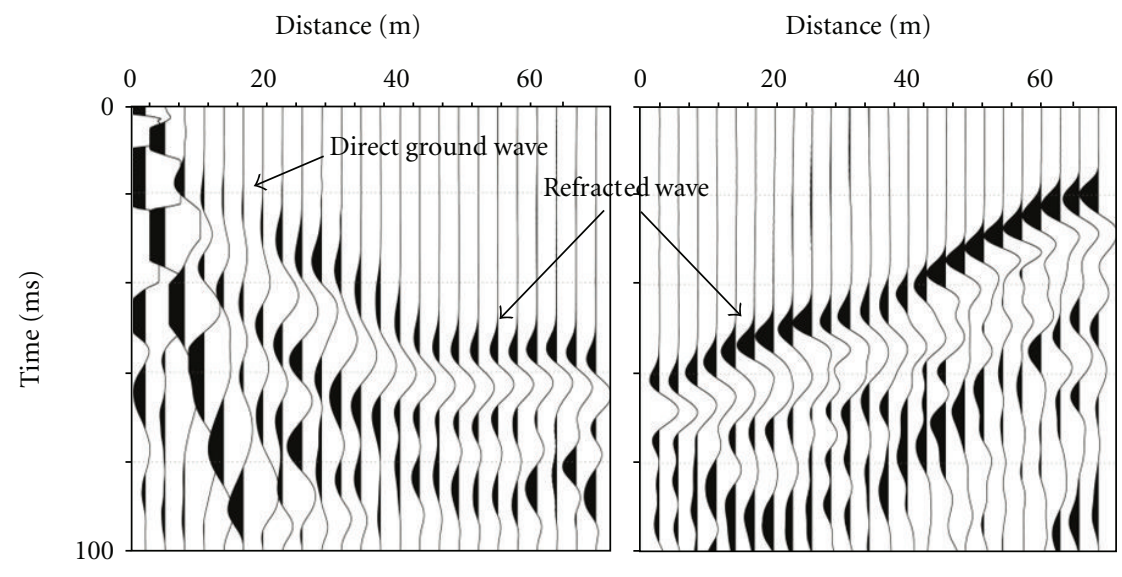

(a)

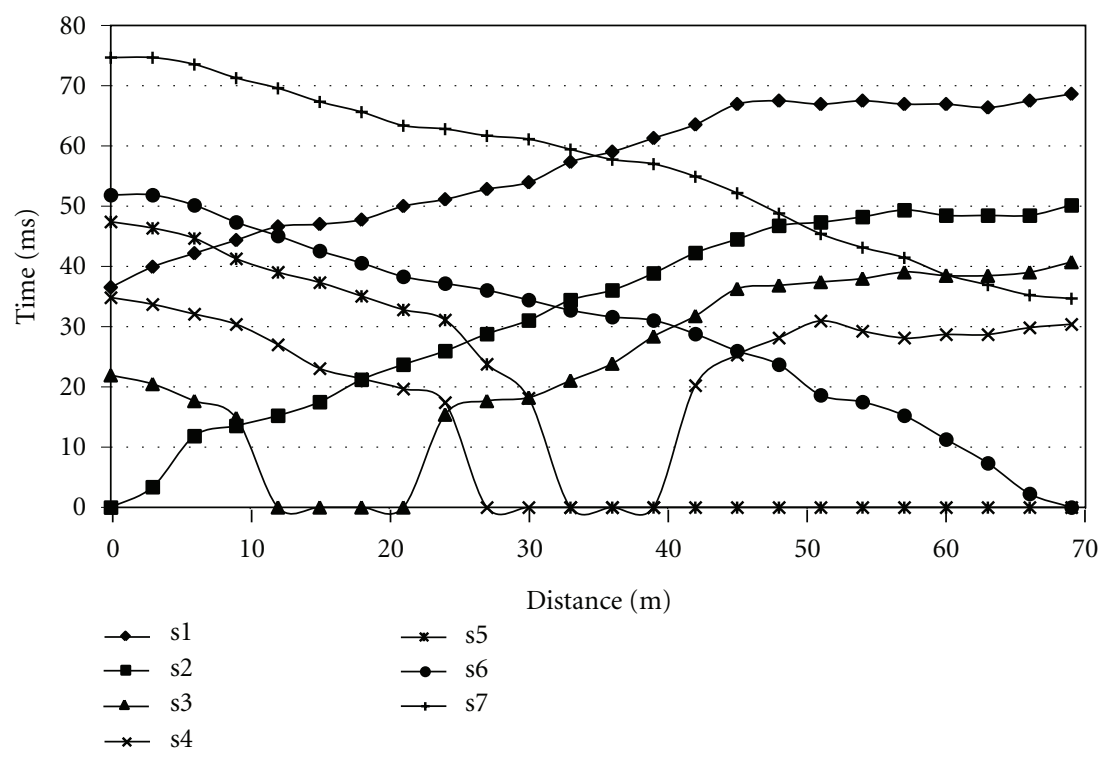

(b)

Figure 6: (a) Shots, s1 and s6, of seismic refraction line 8. (b) First arrivals of line 8.

The first arrivals were picked by hand and rechecked several times to improve accuracy. In Figure 6(a), shots s2 and $s 7$ of line 8 are shown. The most important problem encountered was due to the direct wave that, for some shots, travelled through the road concrete.

The inversion was checked using the delay time method $[10,11]$ integrated, in the case of more than one layer, with the method proposed by Bernabini [12] and seismic refraction tomography based on the SIRT (Simultaneous Iterative Reconstruction Technique) algorithm [13, 14]. The tests showed that the delay time method gave more consistent results with the borehole stratigraphy than the seismic tomography method because of the small number of shots for each line, the lack in some shots of the direct ground wave, and the lateral velocity variation of the bedrock.

The first arrivals were used (see an example in Figure 6(b)) for the calculation of $\mathrm{P}$ wave velocities and delay times. The former were used to drow the seismic refraction stratigraphy (Figures 7(a), 7(c), 7(e), and 8(a)).
Seismic refraction allowed me to survey the first $1-10 \mathrm{~m}$ of soil investigating three layers (Figures 7(a), 7(c), 7(e), and $8(a))$. On the basis of the stratigraphy of boreholes, the seismic velocities were interpreted in terms of lithologies (Figure 5(b)) as described below.

(1) The near surface weathered layer (A1), with velocity of about $500 \mathrm{~m} / \mathrm{s}$ and thickness from 0.5 to $7 \mathrm{~m}$, was linked to the upper part of Unit A drilled with boreholes, which consists of clay-filled deposits.

(2) The second seismic layer (A2), with velocity of about $1000-1100 \mathrm{~m} / \mathrm{s}$ and thickness from 0.5 up to 14 meters, was linked to the lower part of Unit A formed by silty-clay deposits.

(3) The third seismic layer (B), with velocity of 1000$2300 \mathrm{~m} / \mathrm{s}$, was linked to Unit B formed by fairly dense silty-marl. 


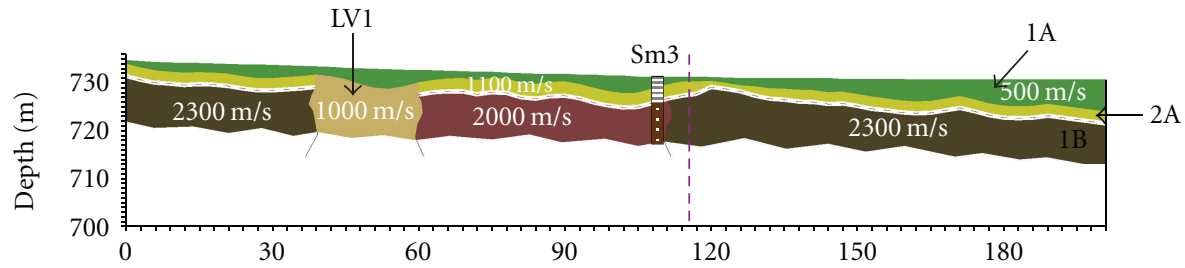

(a)

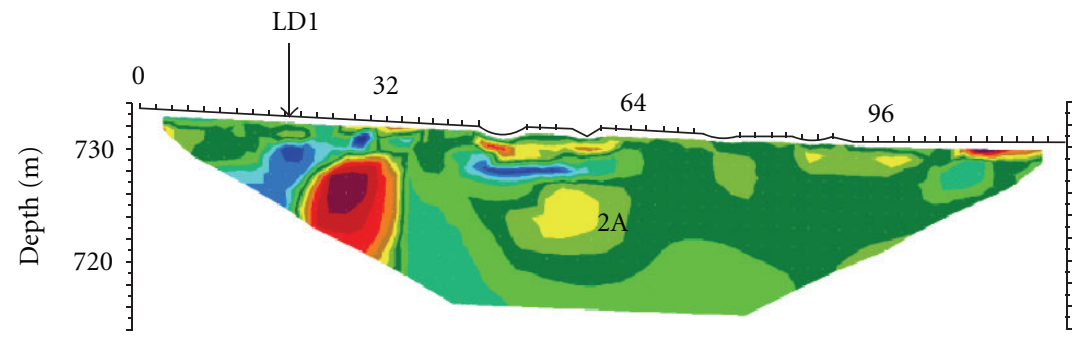

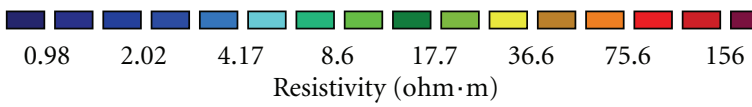

(b)

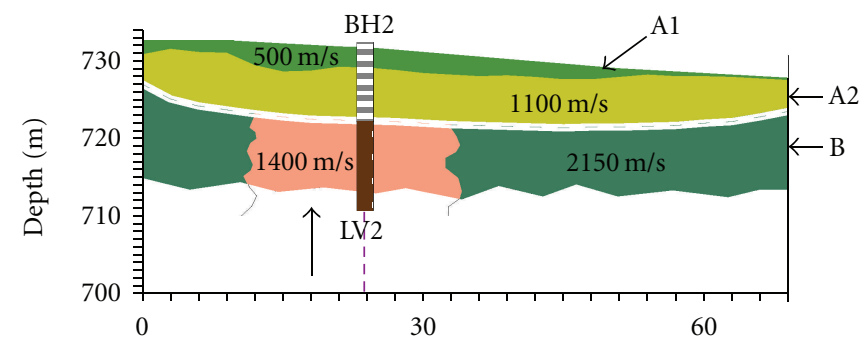

(c)

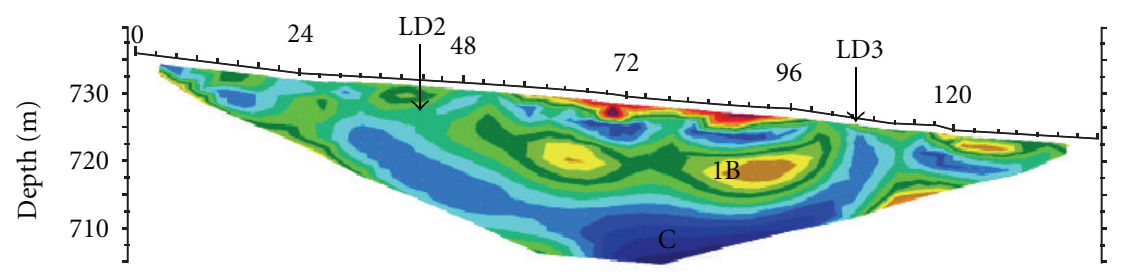

$\square \square \square \square \square \square \square \square \square \square \square \square \square \square \square \square \square$

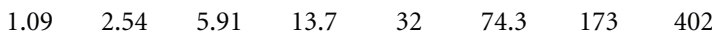

(d)

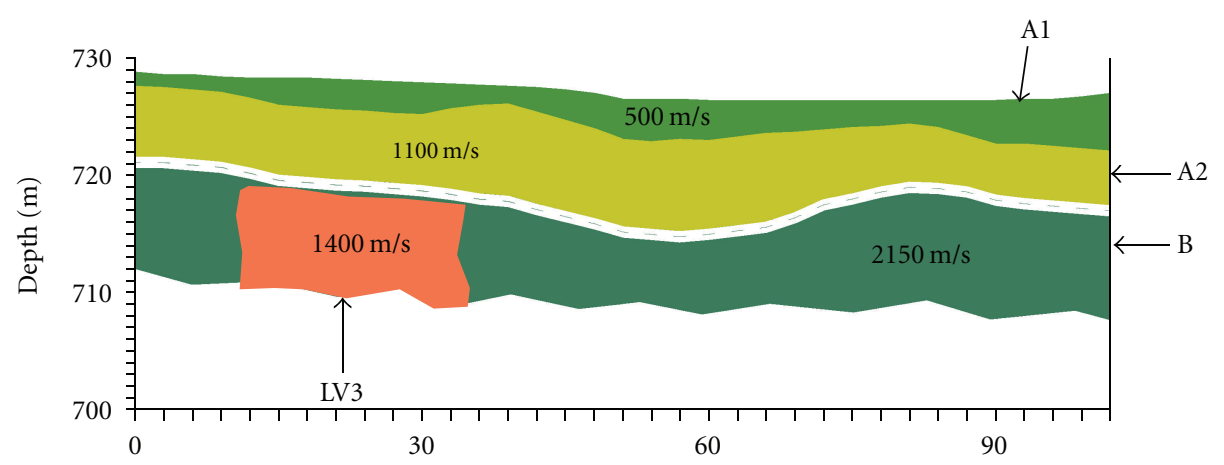

(e)

Figure 7: Continued. 


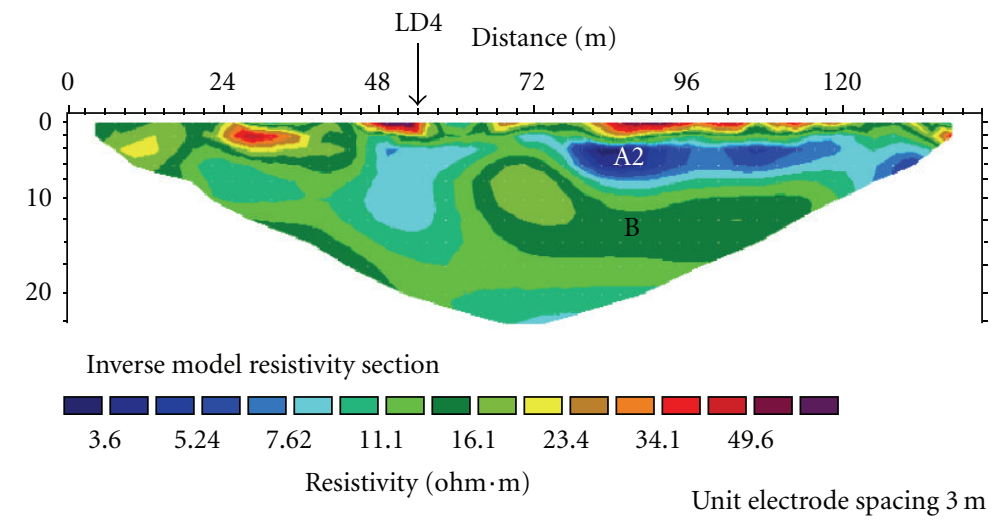

(f)

Figure 7: Seismic refraction profiles ((a), (c) and (e)) detect three layers, the first two (A1 and A2) related to Unit A and the third to Unit B drilled by boreholes; LV indicates low-velocity zones. Electrical resistivity tomography profiles ((b), (d) and (f)) detect four layers, the first two related to Unit A, the third to Unit B, and the fourth (C) to a non drilled shale layer. LD indicates lateral discontinuity of marl formation. Profile locations appear in Figure 5.

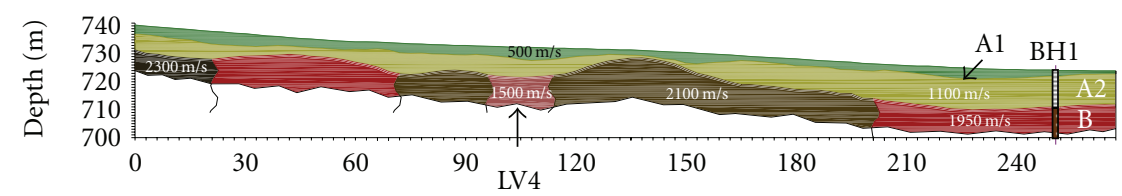

(a)

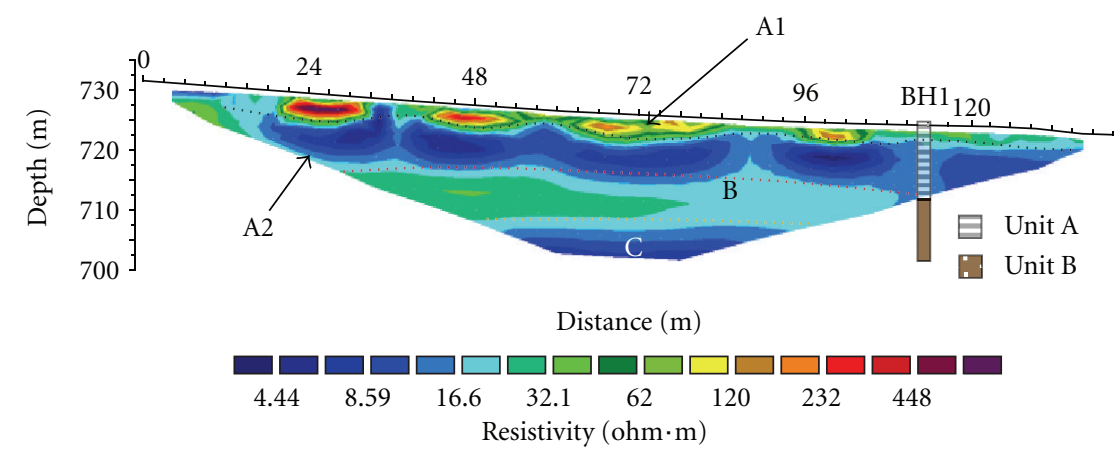

(b)

FIgURE 8: (a) Seismic refraction profile detects two layers of Unit A and the top of Unit B; LV indicates a low-velocity zone. (b) Electrical resistivity tomography profile detects Units A and B and a non drilled shale layer. LD indicates lateral discontinuity of marl formation. Profile locations appear in Figure 5.

The third layer is characterised by marked lateral changes in $\mathrm{P}$ wave velocity, varying between 1000 and $2300 \mathrm{~m} / \mathrm{s}$. The main low-velocity zones in Figures 7(a), 7(c), 7(e) and 8(a) are marked with capital letters LV followed by a number. The couple of seismic profiles with crack locations of Figure 5(a) show a good overlap of the low-seismic-velocity zones with patterns of cracks: in detail, pattern $B$ crosses the profile of Figure 7 (a) in correspondence with the LV1 zone, pattern C crosses profiles of Figures 7(c) and 7(e) in correspondence with the LV2 and LV3 zones respectively.

Because of the lateral velocity changes, I realised that this layer could not be considered bedrock for the remediation plan and that the low velocity zones should be studied in greater detail because low velocities can be due to both rupture zones and to lateral lithology changes.

The ambiguity of the interpretation of low velocity zones of seismic bedrock suggested that I should investigate the area with electrical resistivity tomography (ERT).

3.2. Electrical Resistivity Tomography. The area was surveyed with 9 electrical resistivity tomography (ERT) profiles (Figure 5(c)) during two campaigns. Profiles 1-6 (green lines in Figure 5(c)) were acquired in the first campaign and located more or less in the same position as the seismic refraction profiles with the objective to use the data for a joint interpretation. The profiles 7-9 (dot lines in Figure 5(c)) 
TABle 2

\begin{tabular}{lc}
\hline ERT Survey & \\
\hline Instrument & Syscal Pro Switch-IRIS Corporation \\
Electrode & 48 \\
Electrode offset & 2 m lines $1-3 ; 3$ m lines $4-$ \\
Spread & Wenner, Schlumberger, pole-dipole \\
\hline
\end{tabular}

were acquired in a second campaign with the objective to increase the depth of investigation. They were located on a slope outside the urban area where the topographic level was lower than the others and pole-dipole spread was used to increase the depth of investigation for comparable line length, which was constrained by the available space.

In the urban area the electrodes were coupled with the sedimentary formation, drilling the insulated paving with holes $40-70 \mathrm{~cm}$ deep and $2 \mathrm{~cm}$ in diameter. The acquisition parameters are listed in Table 2. The electrode spread of lines $1-3$ was $2 \mathrm{~m}$ and for all the others $3 \mathrm{~m}$. The $2-3 \mathrm{~m}$ spread was chosen on the basis of seismic refraction results that indicated a bedrock at $2-12 \mathrm{~m}$.

The data were processed with the well-tested smoothness-constrained least-squares approach $[15,16]$ that seeks the theoretical solution which best fits with the actual data. Minimization error was obtained from a Gauss-Newton algorithm based on an iterative process. The inversion was started from a homogeneous model, taking into account the actual topography along the profile that was modelled with model blocks with a moderately damped distorted grid.

ERT profiles investigated a depth of about $20-25 \mathrm{~m}$, detecting 4 main electrolayers (Figures 7(b), 7(d), 7(f) and Figure $8(\mathrm{~b})$ ). Starting from the topographic surface, the four layers are characterized by resistivities of 60,10 , $20-40$, and $10 \Omega \cdot \mathrm{m}$, respectively. From the correlation of ERT stratigraphy with core boreholes the ERT data were interpreted as described below.

(1) The first two electrolayers are related to Unit A, where the first electrolayer (A1) consists of reworked material including asphalt and utilities and the second one (A2) of shale.

(2) The third electro-layer is related to Unit B, which is formed mainly by shale-marl. The resistivity features of this layer show us that it is a few meters thick and laterally discontinuous.

(3) The fourth layer, marked C in Figures 7 and 8, is not univocally interpretable in terms of lithology because it was not drilled by boreholes. Taking into account the resistivity value of this layer, that is equal to the second one, and the large-scale geological map, which indicates that the study area consists of a succession of shale and marl, I advanced the hypothesis that this layer (marked C in Figures 7 and 8) could be formed by shale-clay.

A perspective mapping of the 4 lines (Figure 9) acquired on the sloping area (Figure 5(c)) shows a shallow subsurface with the same features as the urban area. Here the marl is laterally discontinuous and probably dips in the same direction as the topography. From the ERT images, the discontinuous marl layer is merged into a shale formation. The main lateral discontinuities of marl in Figures 7(b), 7(d), $7(\mathrm{f})$, and 8 (b) are marked with capital letters LV (lateral discontinuity) followed by a number. Coupling the marl lateral discontinuities with pattern of cracks, I observed that the crack pattern $\mathrm{B}$ crosses the profile $7 \mathrm{~B}$ in correspondence with discontinuity LD1; the crack pattern $\mathrm{C}$ crosses the profiles $8 \mathrm{D}$ and $\mathrm{F}$ in correspondence with LD2 and LD4.

The ERT data confirm that the near surface formation is formed by a shale-marl succession, as indicated by the large-scale geological map, and that the marl layer cannot be considered bedrock for the remediation plan because of its lateral discontinuity and its small thickness.

\section{Joint Interpretation}

In Figure 10, a synthesis of the data interpretation is shown. The crack survey detected three main patterns of cracks with directions perpendicular to each other. The cracks bound the unstable area. The GPS shows that, in the unstable area, the vertical component of the soil displacement is more prevalent than the horizontal. The direction of the horizontal component is indicated by the arrow in Figure 10. These results agree with the hypothesis that the instability is due to the compacting of near-surface strata caused by the water table drawdown following long periods of drought and the pumping of water in the proximity of two restructured buildings.

The correlation of the seismic with the electrostratigraphy of profiles acquired in the same position shows a good overlap of the geometries of the first three layers as shown in Figures 7 and 8. Combining ERT and seismic refraction data, the subsurface sedimentary structures up to $15-20 \mathrm{~m}$, which consist of 4 layers, were reconstructed with good accuracy. The stratigraphy was investigated with the same resolution by both geophysical surveys. The lithology of each layer was defined by correlation of geophysical data with coring borehole stratigraphies. In detail, starting from the topographic surface, the first layer (A1 in Figures 7 and 8) is linked to the weathered layer that consists of fill materials including utilities. This layer is characterized by a resistivity greater than $60 \Omega \cdot \mathrm{m}$ and a P wave velocity of $400-500 \mathrm{~m} / \mathrm{s}$. The second layer, with resistivity of about $10 \Omega \cdot \mathrm{m}$ and $\mathrm{P}$ wave velocity of 1100 (A2 in Figures 7 and 8), is shale that includes thin layers of limestone and sandstone. From BH2 borehole I knew that some thin permeable layers are filled by overpressured water. Layer 3 was drilled by boreholes and detected with seismic refraction and ERT. This layer consists of fairly dense shale-marl and is characterized by a resistivity of $20-40 \Omega \cdot \mathrm{m}$ and velocity from 1000 to $2300 \mathrm{~km} / \mathrm{s}$. Below the marl, ERT detected Unit C (Figures 8(b), 8(c), and 8(e)) with a resistivity of $10 \Omega \cdot \mathrm{m}$ that I interpreted as shale.

Combining the ERT and seismic data I constrained the interpretation of low-velocity zones (LV) detected by seismic reflection asserting that the low-velocities are due to lateral discontinuities of marl. The map location of the main low velocity zones of Figure 10 shows that they are positioned 


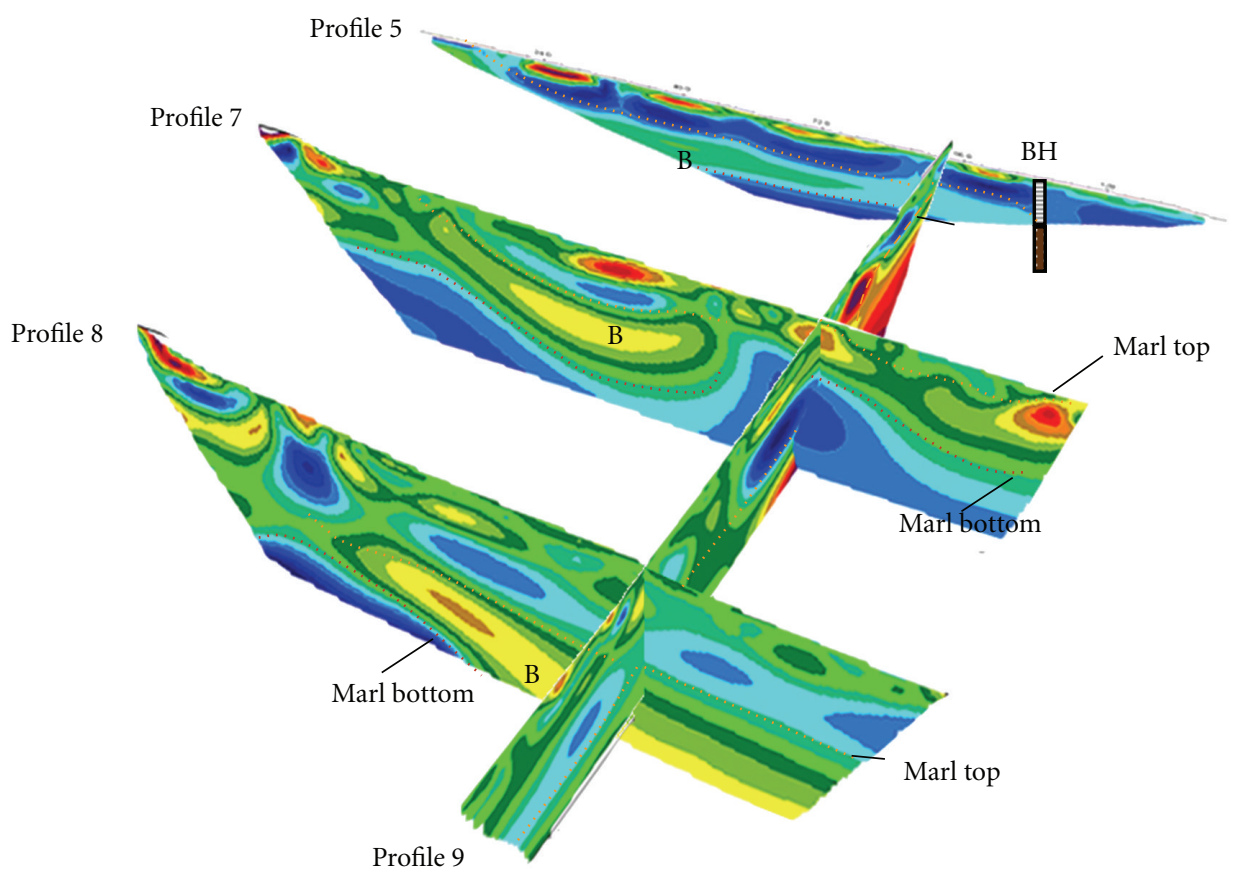

FIGURE 9: Perspective map of ERT profiles located in sloping area. Profile location in Figure 5(c).
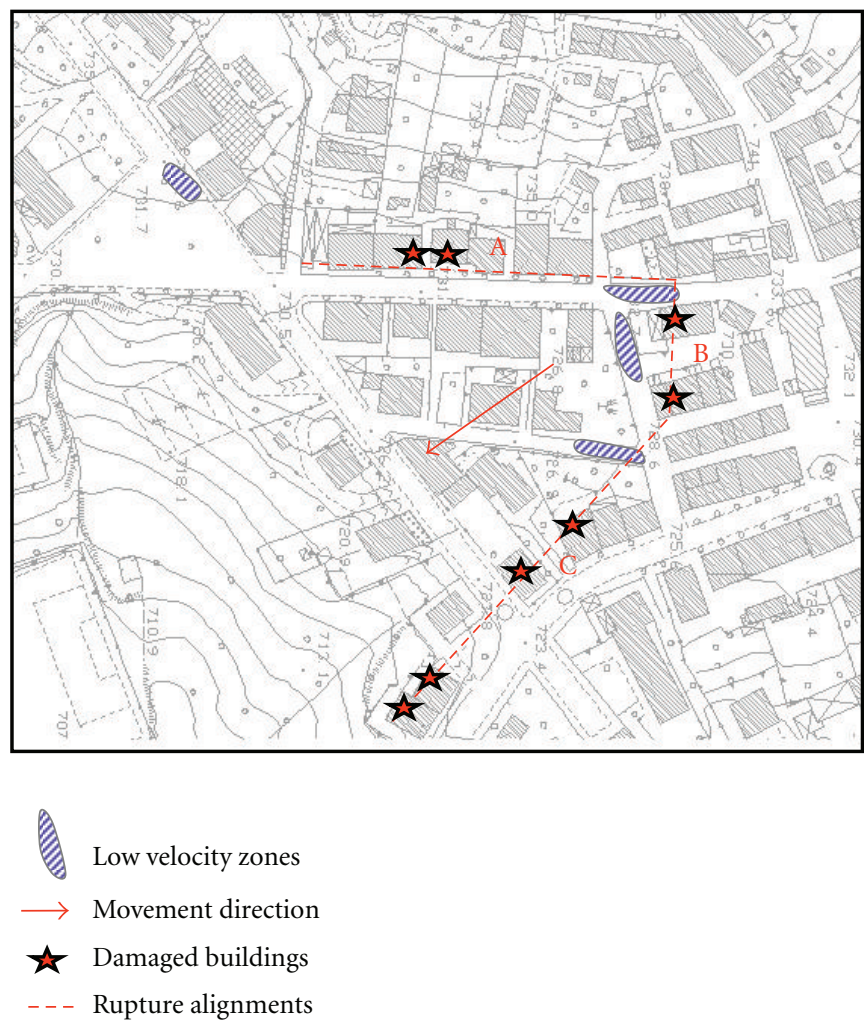

FIGURE 10: Location of main rupture zones, buildings affected by marked damage, and low-velocity zones detected by seismic refraction. The arrow indicates the main direction of movement in the area and the dashed lines the rupture alignments. 
near the crack pattern B. From geophysical investigations, I can infer that the marl layer, although characterized by high seismic velocity (1900-2200 m/s), cannot be regarded as bedrock for planning of environmental recovery of the area because of its lack of lateral continuity. Furthermore, since the lateral discontinuities are located in correspondence of fractures, I can assert that the detachments occurred in the greatest weakness zones of the subsoil.

The buried organic humus layer at a depth of $3.5-5 \mathrm{~m}$ detected by borehole $\mathrm{BH} 1$ and the marl that is laterally discontinuous and embedded into shale led us to suppose that the near-surface units probably consist of non-in-situ formations mobilized by a past landslide.

\section{Discussion and Conclusion}

In this paper, I have proposed a multidisciplinary approach to perform an exhaustive analysis of an area affected by instability problems for solving two main problems: to depict the stratigraphy of the near surface sediments and to advance a hypothesis on the cause of instability. The former was the more difficult issue because both landslide and terrain compacting can induce ground motion which is the cause of building damage.

The study has shown that, for urban sites characterized by a complex geology, many ambiguities of data interpretation can be overcome with a joint interpretation of data performed with direct and indirect methods. In this particular case the difficulties in solving the problems were due to both the complexity of the geology and the urbanization of the area that have not fostered an optimal survey plan. Therefore, the planning of the surveys was the result of a complex process that started from the initial knowledge of the soil and was improved over time with newly acquired knowledge of the setting of the study area.

This study made me realize the importance of the mapping with fractures visible on the road and buildings and the interviews with the owners. The mapping of the fractures allowed me to separate the unstable from the stable area, observe an organic unity in the distribution of fractures, and conclude that the degree of damage to buildings is independent of their age; the interview with the owners allowed me to reconstruct the evolution of instability.

The joint interpretation of the direct and indirect surveys resulted in establishing boundaries of the area affected by instability phenomena, defining the main direction of ground motion, and depicting the stratigraphy of the first 10-20 of soil.

The electrical imaging, in addition to confirming the results obtained by seismic, allowed me to remove the uncertainty in the interpretation of the low velocities of seismic bedrock, because the images clearly show that low velocities occur in zones where the marl was absent. This result allowed me to assert that the marl layer cannot be considered bedrock for the recovery plan. Seismic refraction is shown to be a useful tool with which to infer the P velocity of the formation and the ERT for lithological characterization of formations that are not drilled.
The joint analysis of the data did not allow me to uniquely identify the cause of instability, because the evidence can be justified both by the reactivation of an old landslide and by the compaction of sediments. In detail, the stratigraphy and morphology could lead to hypothesize that the area has been affected by reactivated landslides, while the topographic survey and the long period of drought that occurred just before the instability problem could lead to hypothesize that the instability was due to the compaction of the near surface sediments. Unfortunately, this problem is inherent in the combined use of direct and indirect methods currently available that allow us to photograph the effects of instability and the soil stratigraphy in a time period that is often too short to understand the phenomena and to reduce the ambiguity in determining the causes of instability in a complex situation. Speculatively, I advance the hypothesis that the urban area was built on an old landslide and that the recent instability that occurred within a period of 5-7 years has been caused by compaction of surface sediments. Despite this, the results obtained from the joint interpretation of direct and indirect surveys, can be considered absolutely necessary for effective restoration planning of the area.

For more exhaustive results, the study could be approached with topographic survey and water table monitoring over an extended period of time and involve other disciplines such as GIS and geostatistical methods [17-19] for a classification of the land in additional susceptibility domains.

\section{Acknowledgments}

This research was supported by the municipality of Roccaspinalveti, Italy. The author would like to thank engineers Emliano Oliveti and Alessandra Di Battista for their help in the acquisition and processing of the data and Professor M. Crespi (Sapienza University of Rome) for his help with the topographic results.

\section{References}

[1] E. Cardarelli, C. Marrone, and L. Orlando, "Evaluation of tunnel stability using integrated geophysical methods," Journal of Applied Geophysics, vol. 52, no. 2-3, pp. 93-102, 2003.

[2] K. Koch, J. Wenninger, S. Uhlenbrook, and M. Bonell, "Joint interpretation of hydrological and geophysical data: electrical resistivity tomography results from a process hydrological research site in the Black Forest Mountains, Germany," Hydrological Processes, vol. 23, no. 10, pp. 1501-1513, 2009.

[3] L. Orlando and G. Pelliccioni, "P and PS data to reduce the uncertainty in the reconstruction of near-surface alluvial deposits (Case study-Central Italy)," Journal of Applied Geophysics, vol. 72, no. 1, pp. 57-69, 2010.

[4] H. J. Mauritsch, W. Seiberl, R. Arndt, A. Römer, K. Schneiderbauer, and G. P. Sendlhofer, "Geophysical investigations of large landslides in the Carnic Region of southern Austria," Engineering Geology, vol. 56, no. 3-4, pp. 373-388, 2000.

[5] E. Cardarelli, M. Cercato, and G. Di Filippo, "Assessing foundation stability and soil-structure interaction through integrated geophysical techniques: a case history in Rome (Italy)," Near Surface Geophysics, vol. 5, no. 2, pp. 141-147, 2007. 
[6] D. Colombo and M. de Stefano, "Geophysical modeling via simultaneous joint inversion of seismic, gravity, and electromagnetic data: application to prestack depth imaging," Leading Edge, vol. 26, no. 3, pp. 326-331, 2007.

[7] M. Dobroka, A. Gyulai, T. Ormos, J. Csokas, and L. Dresen, "Joint inversion of seismic and geoelectric data recorded in an underground coal mine," Geophysical Prospecting, vol. 39, no. 5, pp. 643-665, 1991.

[8] L. A. Gallardo and M. A. Meju, "Characterization of heterogeneous near-surface materials by joint $2 \mathrm{D}$ inversion of $\mathrm{dc}$ resistivity and seismic data," Geophysical Research Letters, vol. 30, no. 13, pp. 1-4, 2003.

[9] W. Hu, A. Abubakar, and T. M. Habashy, "Joint electromagnetic and seismic inversion using structural constraints," Geophysics, vol. 74, no. 6, pp. R99-R109, 2009.

[10] L. Gardner, "An area plan of mapping subsurface structure by refraction shooting," Geophysics, vol. 4, pp. 247-250, 1939.

[11] F. S. Grant and G. F. West, Interpretation Theory in Applied Geophysics, McGraw-Hill, New York, NY, USA, 1965.

[12] M. Bernabini, "Alcune considerazioni sui rilievi sismici a piccole profondità," Bollettino di Geofisica Teorica e Applicata, vol. 26, pp. 106-118, 1965.

[13] D. L. Lager and R. J. Lytle, "Determining a subsurface electromagnetic profile from high-frequency measurements by applying reconstruction-technique algorithms," Radio Science, vol. 12, no. 2, pp. 249-260, 1977.

[14] K. A. Dines and R. J. Lytle, "Computerized geophysical tomography," Proceedings of the IEEE, vol. 67, no. 7, pp. 10651073, 1979.

[15] A. C. Tripp, G. W. Hohmann, and C. M. Swift, "Twodimensional resistivity inversion," Geophysics, vol. 49, no. 10, pp. 1708-1717, 1984.

[16] M. H. Loke and R. D. Barker, "Rapid least-squares inversion of apparent resistivity pseudosections by a quasi-Newton method," Geophysical Prospecting, vol. 44, no. 1, pp. 131-152, 1996.

[17] A. Carrara, M. Cardinali, R. Detti, F. Guzzetti, V. Pasqui, and P. Reichenbach, "GIS techniques and statistical models in evaluating landslide hazard," Earth Surface Processes and Landforms, vol. 16, no. 5, pp. 427-445, 1991.

[18] F. Guzzetti, A. Carrara, M. Cardinali, and P. Reichenbach, "Landslide hazard evaluation: a review of current techniques and their application in a multi-scale study, Central Italy," Geomorphology, vol. 31, no. 1-4, pp. 181-216, 1999.

[19] N. Santacana, B. Baeza, J. Corominas, A. de Paz, and J. Marturiá, "A GIS-based multivariate statistical analysis for shallow landslide susceptibility mapping in La Pobla de Lillet Area (Eastern Pyrenees, Spain)," Natural Hazards, vol. 30, no. 3, pp. 281-295, 2003. 

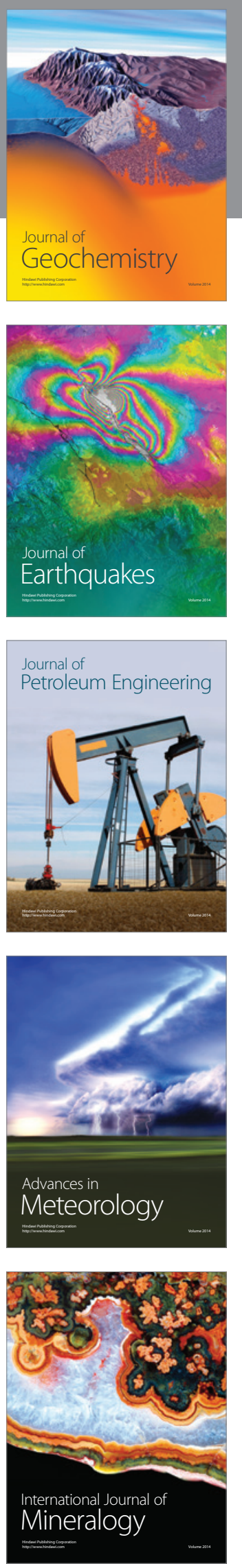
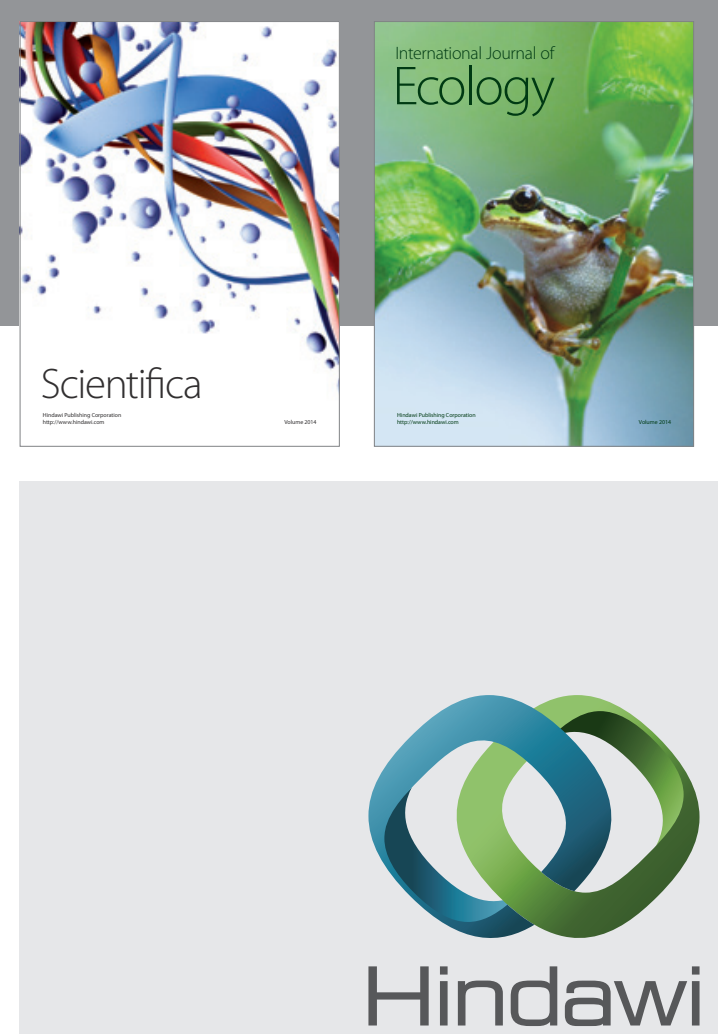

Submit your manuscripts at http://www.hindawi.com
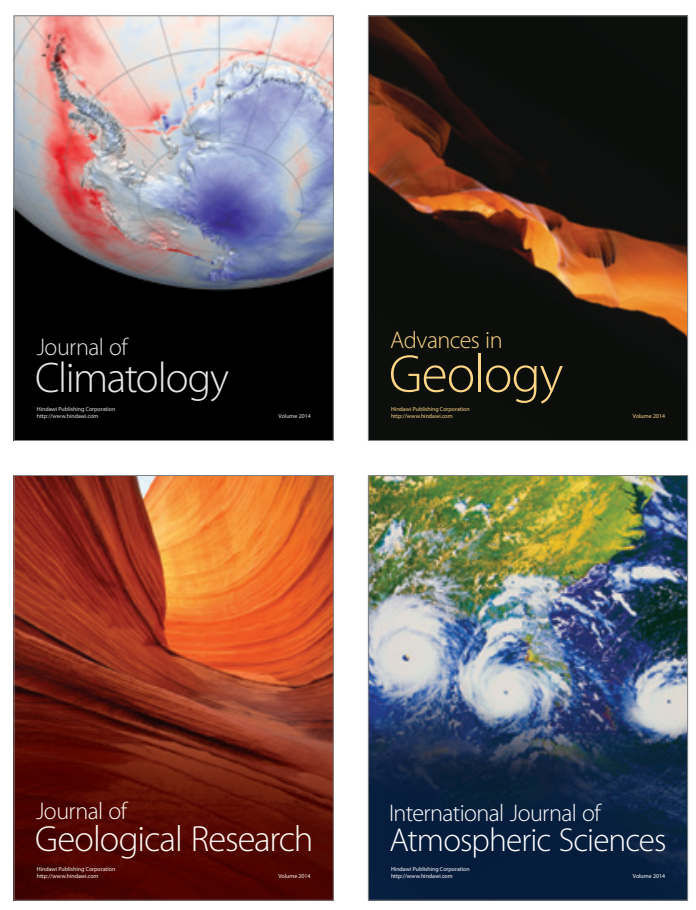
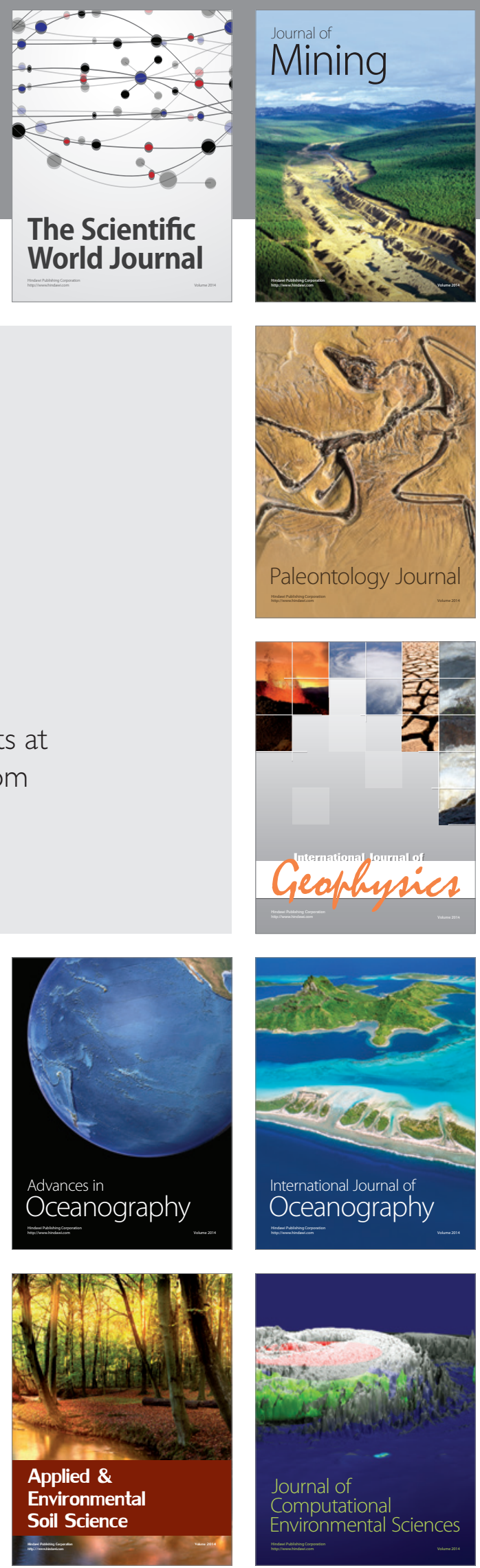